\title{
Is fluorescence of biogenic aerosols an issue for Raman lidar measurements?
}

\author{
Franz Immler and Otto Schrems \\ Alfred Wegener Insitute for Polar and Marine research, Bremerhaven, Germany
}

\begin{abstract}
During a measuring campaign in Lindenberg/Germany $\left(14.5^{\circ} \mathrm{E}, 52.5^{\circ} \mathrm{N}\right)$ in August 2003, we observed an extended aerosol layer in the upper troposphere with our mobile Aerosol Raman Lidar (MARL). Backward trajectories indicated that this was a plume originating from forest fires. Water vapor Raman measurements performed with the same lidar showed a large discrepancy with co-located radiosonde measurements, which were not observed in undisturbed conditions. We interpret the unexpected properties of these aerosols as fluorescence induced by the laser beam at organic components of the aerosol particles. The detection of fluorescence from ambient aerosol with lidar systems has not yet been reported before. However, organic compounds such as polycyclic aromatic hydrocarbons sticking to the aerosol particles, or bioaerosol such as bacteria, spores or pollen fluoresce when excited with UV-radiation in a way that is detectable by our lidar system. Therefore, we conclude that fluorescence from organic material released by biomass burning induces inelastic backscatter signals which could be observed with the lidar. It provides for a new method to characterize atmospheric aerosols and should be taken into account when performing water vapor measurements with a Raman lidar.
\end{abstract}

\section{INTRODUCTION}

The intrinsic fluorescence of atoms and molecules offers interesting opportunities for lidar remote sensing of the atmosphere. Generally, fluorescence is a very effective process that promises a high sensitivity for the remote detection of trace constituents in the atmosphere. Despite their extremely low concentration on the order of $10^{5} \mathrm{~cm}^{-3}$ hydroxyl $(\mathrm{OH})$ molecules and metal atoms such as sodium, potassium or iron have been detected by resonant fluorescence in the mesosphere in $85 \mathrm{~km}$ altitude and allow the determination of the temperature and wind at these altitudes. ${ }^{123}$

In the lower atmosphere however, fluorescence by most atoms or molecules in the gas phase is severely hampered by collisional quenching of the exited states due to the high pressure. Nonetheless, larger organic molecules are still capable to fluoresce and allow interesting applications near or at the earth's surface. For instance, contamination of soils with petroleum products is detected in situ with high sensitivity using fluorescence ${ }^{4}$ and fluorescence lidars are used for remotely detecting oil spills, phytoplankton and chlorophyll on the surface of the sea. ${ }^{5}$

Aerosol particles that contain organic pollutant may as well fluoresce when excited with a UV laser beam and could therefore interfere with Raman lidar applications. Hegglin et al. ${ }^{6}$ reported that they observed broad fluorescence spectra from single levitated sulphuric acid droplets that contained aliphatic hydrocarbons, alcohols, aldehydes, ketones or organic acids and conclude that ambient aerosol which often contain a significant amount of these organic compounds should fluoresce.

The investigation of fluorescence from polycyclic aromatic hydrocarbons adsorbed on suspended particles was pioneered by Allegrini and Omenetto ${ }^{7}$ and the group of Niessner. ${ }^{8}$ The fluorescence spectra of Benzo $[a]$ pyrene (BaP, $C_{20} H_{12}$ ) in water for example, shows a broad band covering the $407 \mathrm{~nm}$ region when excited at $355 \mathrm{~nm}^{9}$ and therefore could in principal be detected with a typical set-up used for water vapor Raman lidars that are based on a Nd:YAG laser. $\mathrm{BaP}$ is an ubiquitous product of incomplete combustion and is stable in the atmosphere. $\mathrm{BaP}$ and other PAHs adsorbed on soot in a smoke plume are known to persist for many days in the atmosphere. ${ }^{10}$

Further author information: (Send correspondence to Franz Immler.)

E-mail: fimmler@awi-bremerhaven.de, Alfred-Wegener-Institut, Am Handelshafen 12, 274570 Bremerhaven, Germany, Telephone: +493312882149 
In polluted air $\mathrm{BaP}$ was found in amounts of $200 \mathrm{pg} / \mathrm{m}^{-3} .{ }^{11}$ The presence of $\mathrm{BaP}$ and other PAHs in cigarette smoke is not only one of the reasons for the carcinogenic effect of smoking, they are also the cause for the fluorescence exhibited by the smoke of tobacco leaves. ${ }^{12}$ This is one example for a biomass burning aerosol that fluoresces when irradiated with UV light. Besides in-situ detection, the remote detection of disseminated spores by a fluorescence lidar up to a distances of several kilometers have been reported. ${ }^{13}$

On the other hand, little is known on the fluorescence of atmospheric aerosol from natural sources. Here, we report the observation of aerosol layers by a ground based water vapor Raman lidar system that created enhanced signals in the water vapor channel. We attribute these signal enhancements to laser induced fluorescence (LIF) created by the aerosol particles. After briefly describing the methods used for these observations we will in detail discuss why we think that aerosol could create inelastic scattering that interferes with water vapor Raman measurements. Finally, we discuss the problems and chances that the fluorescence of aerosols offer for atmospheric research.

The data presented here was obtained during the campaign MARL@MOL which took place from May to October 2003 at the Meteorological Observatory Lindenberg (MOL) in Germany $\left(14.5^{\circ} \mathrm{E}, 52.5^{\circ} \mathrm{N}\right)$.

\section{INSTRUMENTATION}

The Mobile Aerosol Raman Lidar (MARL) of the Alfred Wegener Institute (AWI) is designed for measurements of aerosols and water vapor in the stratosphere and upper troposphere. ${ }^{14}$ It detects light backscattered by molecules and condensed matter in the atmosphere from outgoing laser beams at $532 \mathrm{~nm}$ and $355 \mathrm{~nm}$. Inelastic Raman backscatter from nitrogen is detected at $387 \mathrm{~nm}$ and $607 \mathrm{~nm}$ and allows the direct retrieval of the aerosol extinction coefficient $\alpha .{ }^{15}$ An additional detection channel at $407 \mathrm{~nm}$ detects vibrational Raman scattering from $\mathrm{H}_{2} \mathrm{O}$ molecules and allows the determination of the water vapor mixing ratio profiles up to about 8 to $10 \mathrm{~km}$ at night time. The system was built in 1995 but has received considerable upgrades with respect to the optic, the electronic and software in recent years.

The emitter of our lidar is a Nd:YAG laser with frequency doubling and tripling, generating laser pulses with about $300 \mathrm{~mJ}$ at both $355 \mathrm{~nm}$ and $532 \mathrm{~nm}$ with a repetition rate of $30 \mathrm{~Hz}$ and a pulse duration of $8 \mathrm{~ns}$. The receiver is based on a Cassegrain telescope with $1.1 \mathrm{~m}$ aperture. The light is separated into its planes of polarization (perpendicular and parallel with respect to the polarization of the laser) and coupled into two fibre bundles with a diameter of $4 \mathrm{~mm}$ which transport the light to the 10-channel polychromator. This instrument separates different wavelengths from a parallelized beam using dichroic mirrors and narrowband interference filters. The latter are used to suppress background light and have a bandwidth of $0.15 \mathrm{~nm}$ for the $532 \mathrm{~nm}$ channels and $1 \mathrm{~nm}$ for the $355 \mathrm{~nm}$ channel. The nitrogen Raman channels are also equipped with filters that allow daylight measurement with a bandwidth of $0.15 \mathrm{~nm}$ and $1 \mathrm{~nm}$ for the $607 \mathrm{~nm}$ and the $387 \mathrm{~nm}$ channel, respectively. The only channel that cannot be used during daylight is the water vapor Raman channel at 407 $\mathrm{nm}$ which is filtered by a rather broad filter of $5.7 \mathrm{~nm}$ bandwidth. The reason for this is that due to the very low signal intensity of this channel, measurements of the water vapor in the region of interest for our studies, which is the upper troposphere and lower stratosphere, would not be possible during daylight anyway. The details of the polychromator specifications are summarized in table 1.

The signals are measured with Hamamatsu Photomultipliers and digitized using Licel transient recorders. These are equipped with parallel photon counting (pc) and analog (a) measurement capabilities for the elastic channels. The high voltage of the photomultipliers (PMT) is controlled by a Licel unit that allows computer controlled adjustment of the gain. It is automatically switched off in cases of a too large signal peak or dark current (determined from the counting statistics before the laser shot) that could damage the PMTs. The photomultipliers, the data acquisition, and the laser are automatically switched off in case of bad signals, which are generally due to low clouds. In case of rain, which is detected by a separated rain detector, the hatch is closed and the entire system is shut down automatically as well. The lidar can be restarted by a remote command, which may be issued from a remote host via the internet. In fully automatic mode, the system restarts by itself in cases where no severe error had occurred after a given delay time of typically several hours. Depending on the user defined settings, it may also automatically start at a certain time of the day, e.g. after sunset. 
This high degree of automation allows us to perform unattended measurements over at least several days. Therefore, we were able to obtain a large data set of hundreds of hours worth of data with a minimum of manpower. During the MARL@MOL campaign, no more than a few operator hours per week were necessary on average.

Table 1. Specifications of the channels in the polychromator of the Lidar system MARL

\begin{tabular}{|c|c|c|c|c|c|c|c|}
\hline Channel & mode & Wavelength & range & Polarization & peak/nm & bandwidth/nm & Transmission \\
\hline 1 & $\mathrm{a} / \mathrm{pc}$ & 532 & near & $\|$ & 533,3 & 10,2 & $78 \%$ \\
\hline 2 & $\mathrm{a} / \mathrm{pc}$ & 355 & near & $\|$ & 354,7 & 0,7 & $50 \%$ \\
\hline 3 & $\mathrm{a} / \mathrm{pc}$ & 532 & near & $\perp$ & 532,0 & 0,15 & $35 \%$ \\
\hline 4 & $\mathrm{a} / \mathrm{pc}$ & 355 & near & $\perp$ & 354,7 & 1.0 & $45 \%$ \\
\hline 5 & $\mathrm{pc}$ & 607 & near & $\|$ & 607,35 & 0,15 & $35 \%$ \\
\hline 6 & pc & 387 & near & $\|$ & 386,66 & 1 & $45 \%$ \\
\hline 7 & $\mathrm{pc}$ & 407 & near & $\|$ & 407,3 & 5,7 & $63 \%$ \\
\hline 8 & $\mathrm{pc}$ & 532 & far & $\|$ & 532,0 & 0,15 & $35 \%$ \\
\hline 9 & pc & 355 & far & $\|$ & 354,9 & 1 & $52 \%$ \\
\hline 10 & $\mathrm{a}$ & 1064 & near & $\|$ & 1064 & 3 & $77 \%$ \\
\hline
\end{tabular}

\section{WATER VAPOR RETRIEVAL}

A lidar signal measured at the wavelength $\lambda$ is proportional to the total backscatter coefficients at this wavelength $\beta_{\lambda}$ and is described by the following equation:

$$
P_{\lambda}(z)=\frac{C}{z^{2}} O(z) \beta_{\lambda}(z) T^{2}(z)
$$

$C$ summarizes all system constants like laser energy and detection efficiency and $T(z)$ is the transmission term that can be calculated by using Beer- Lambert's law:

$$
T(z)=\exp \left[-\int_{0}^{z} d z^{\prime}\left(\alpha^{A}(z)+\alpha^{M}(z)\right)\right]
$$

$\alpha^{M}$ and $\alpha^{A}$ refer to the extinction coefficients caused by molecular and particle scattering, respectively. $O(z)$ describes the geometric overlap between laser and field of view of the receiving telescope.

Inelastic scattering can be detected at the vibrational Raman lines of atmospheric gases. ${ }^{16}$ The backscatter coefficient $\beta$ is then in good approximation a function of the number density profile of the corresponding molecule $N(z)$ and the cross section $\sigma_{\lambda}$ for Raman scattering which we assume here to be temperature independent. For water vapor the backscatter coefficient is then simply a function of the concentration of water molecules and the backscattering cross section which is constant throughout the atmosphere:

$$
\beta_{407}(z)=N^{\mathrm{H}_{2} \mathrm{O}}(z) * \sigma_{407}^{\mathrm{H}_{2} \mathrm{O}}
$$

Introducing this equation into the lidar equation (1) yields an expression describing the water vapor Raman signal measured by a lidar. In an analogue way the Raman signal from nitrogen which is measured at $387 \mathrm{~nm}$ can be described. The ratio of the water vapor and the nitrogen Raman lidar signal is then proportional to the water vapor mixing ratio $w^{\mathrm{H}_{2} \mathrm{O}}(z)$ :

$$
w^{H_{2} O}(z)=\frac{N^{H_{2} O}(z) M^{H_{2} O} w^{N_{2}}}{N^{N_{2}}(z) M^{d r y}}=C^{\prime} \frac{P_{407}^{H_{2} O}(z)}{P_{387}^{N_{2}}(z)}
$$




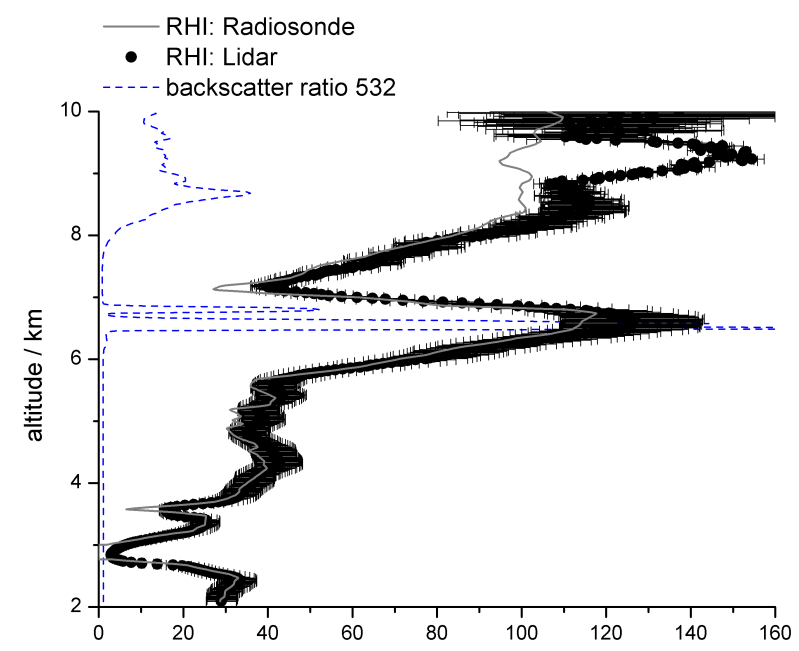

Figure 1. Comparison of water vapor measured with the Raman lidar (black dots) and a radiosonde (solid grey line) from 15 Nov 2003 22:44 UT. The dashed line indicates the backscatter ratio.

$O(z)$ is the same for both lidar signals and thus cancelled. $M^{H_{2} O}$ and $M^{d r y}$ are the molecular weights of water and dry air, respectively. The mixing ratio of nitrogen $w^{N_{2}}$ is constant in the altitude range of interest. However, the calibration constant $C^{\prime}$ needs to be determined by using another independent measurement of water vapor because the system constants cannot be otherwise established.

The German weather service (DWD) provided Radiosonde (Vaisala RS 80) data from four daily launches at the site and these delivered a temperature and humidity profile and allowed the determination of the tropopause height. The water vapor measurement of the RS 80 sondes is based on an improved retrieval algorithm. ${ }^{17}$ This data served for calibrating the water vapor measurements of the lidar which is done by determining $C^{\prime}$ from equation (4) using the water vapor mixing ratio $w_{R S}^{\mathrm{H}_{2} \mathrm{O}}(z)$ determined from the radiosonde profile at an altitude $z_{0}$. An appropriate fit altitude $z_{0}$ is usually found in about $3-5 \mathrm{~km}$ altitude, where the aerosol load is low and the water vapor is still high. During the campaign in Lindenberg we gathered 37 occasions of coincident lidar and RS water vapor measurements. The calibration constant was determined each time and varied less than $5 \%$.

Figure 1 shows a comparison of the water vapor profiles determined with lidar and radiosonde compiled for all co-located measurements available from the MARL@MOL campaign. Generally the two methods agree very good. Larger discrepancies occur at high altitudes where the humidity is high, since the lidar seems to detect more often supersaturated regions than the radiosonde. The thick ice cloud however in $8 \mathrm{~km}$ altitude does not create significant error in the water vapor measurement.

\section{OBSERVATIONS OF INELASTIC SCATTERING BY AEROSOLS}

In early August 2003 extended aerosol layers were observed over Lindenberg with our lidar (fig. 2). In the cloud free (grey) parts the optical depth of this layer reaches values of 0.3 , while the backscatter ratio reaches values of 3. The aerosol does not depolarize. The color index which expresses the wavelength dependence of the aerosol backscatter coefficients $\beta_{\lambda}^{A}$ and is defined as follows:

$$
C_{I}=-\frac{\log \left(\beta_{532}^{A} / \beta_{355}^{A}\right)}{\log (355 \mathrm{~nm} / 532 \mathrm{~nm})}
$$

This value varies between 0.3 and 0.7. Hence, the optical properties are typical for a biomass burning aerosol. ${ }^{18}$ The measured optical properties are well matched by an polluted model aerosol ${ }^{19}$ with an effective radius of $0.3 \mu \mathrm{m}$ and a number concentration of $100 \mathrm{~cm}^{-3}$. This corresponds to a total aerosol mass on the order of 


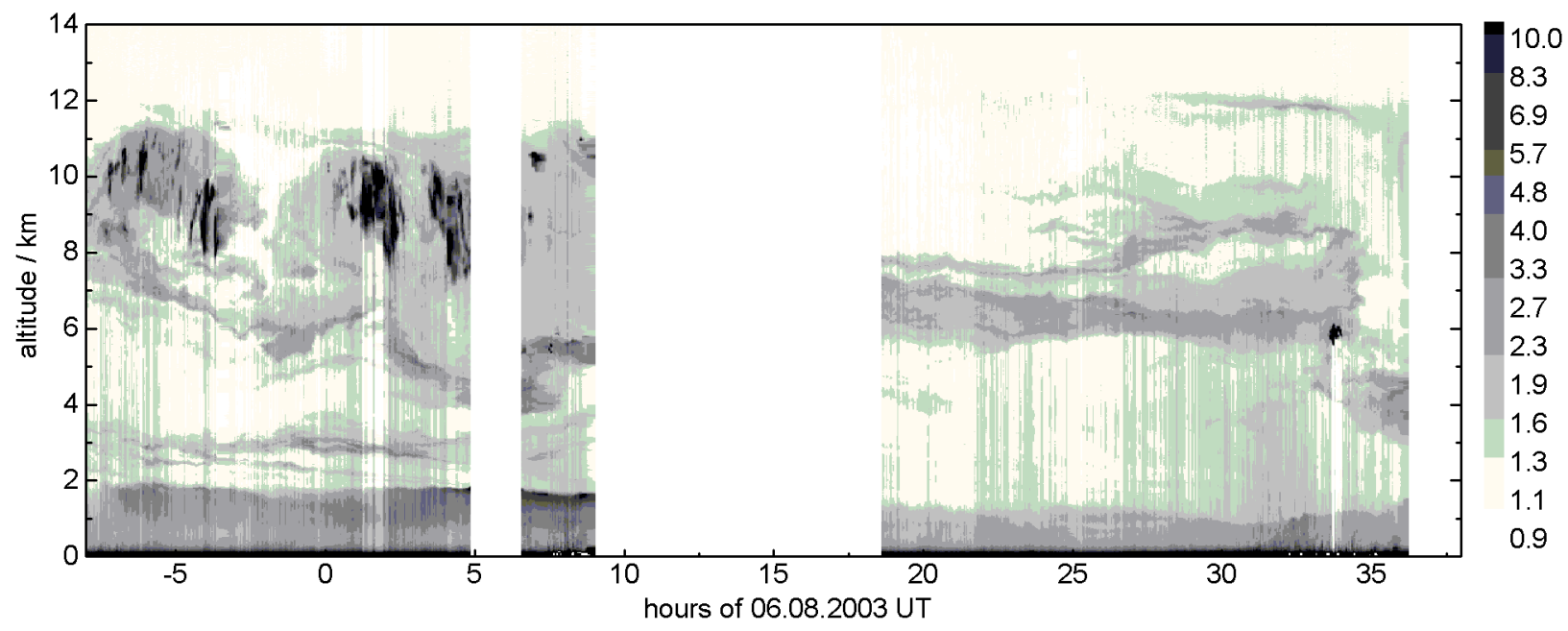

Figure 2. Time versus altitude plot of lidar backscatter ratio at $532 \mathrm{~nm}$ from 5 Aug 2003, 15:00 UT to 7 Aug 2003, 14:00 UT.

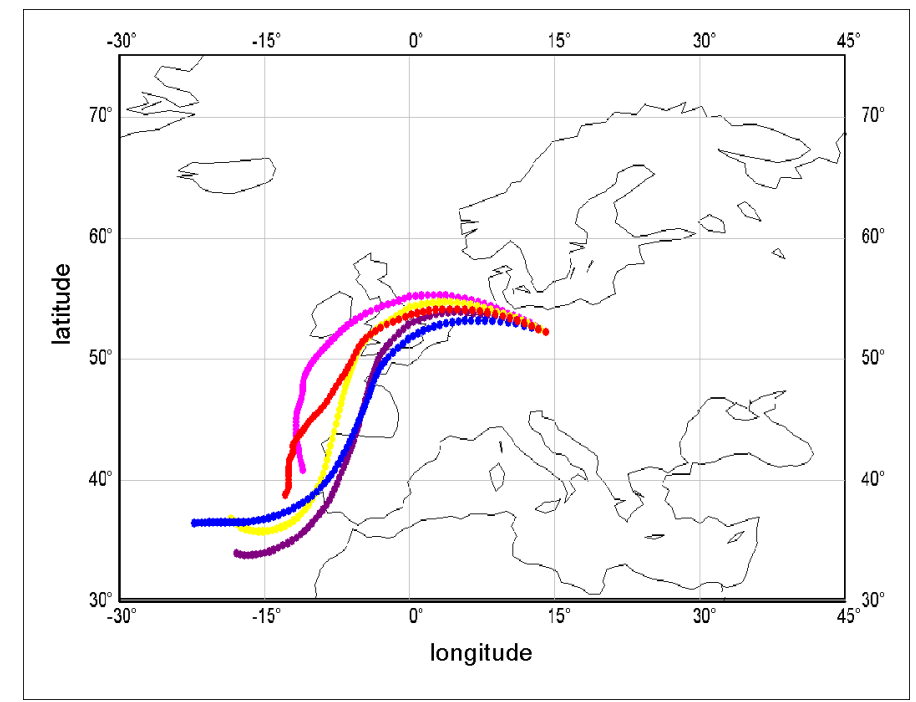

Figure 3. Backward trajectories calculated for Lindenberg, 05 August 2003, 18:00 UT.

$5 \mu \mathrm{g} \mathrm{m}^{-3}$. In early August 2003 extended forest fires burned in Portugal. The backward trajectories shown in figure 3 give a clear indication, that the aerosol which we detected in Lindenberg were smoke plumes from these forest fires.

On that occasion we observed a significant difference between the water vapor profiles determined with the lidar and the radiosonde. This is demonstrated in figure 4. The right panel shows the relative humidity above ice (RHI) determined from both instruments. The difference is very large throughout most of the troposphere and is much larger than found under undisturbed conditions (fig. 1). The left plot of fig 4 shows the difference of the water vapor mixing ratio (in $\mathrm{g} / \mathrm{kg}$ ) The dashed line is the backscatter ratio at $532 \mathrm{~nm}$ which is a measure for the content of aerosol which obviously correlates with the error in the water vapor retrieval of the lidar. This correlation suggests that the aerosol interferes with the water vapor Raman channel and the question is why does it occur? Aerosol of any types have not yet been reported to strongly interfere with water vapor 


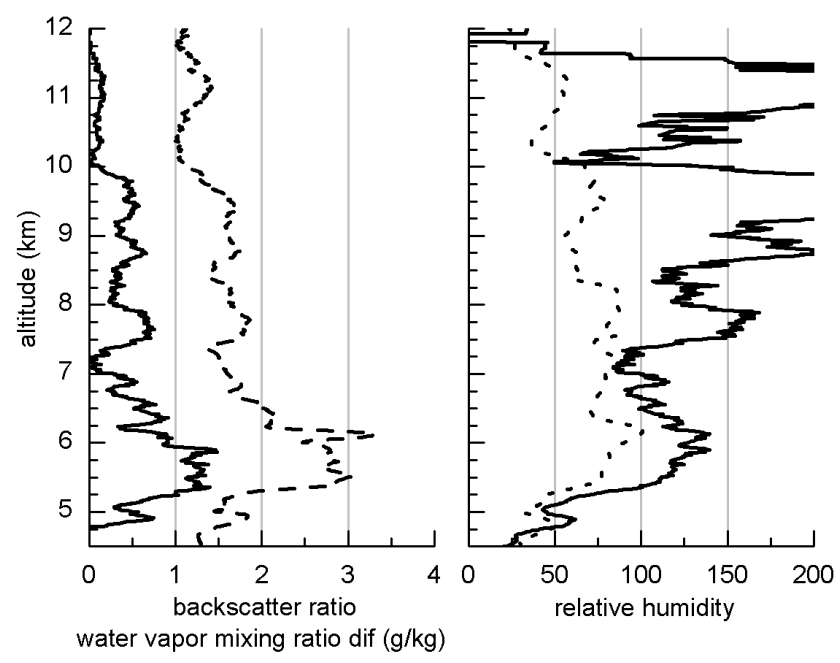

Figure 4. Water vapor measurements with lidar and radiosonde of 05 Aug 2003, 22:38 UT, mean of 20,000 shots (approx. 10 min.) The panel to the left show the difference of the water vapor mixing ration (WVMR) between lidar and radiosonde in $\mathrm{g} / \mathrm{kg}$. The dashed line depicts the backscatter ratio at $532 \mathrm{~nm}$. The plot to the right shows the relative humidity above ice determined from both instruments.

Raman lidar measurements. In 2000 we have performed measurements with the same system aboard the research vessel Polarstern. Around $10^{\circ} \mathrm{N}$ we observed strong layers of Saharan dust in about the same altitude as the Portuguese forest fires discussed here. There is no indication of an interference of the aerosol with the water vapor measurements whatsoever in the Saharan dust case. $^{20}$

As was demonstrated in figure 1 there is no cross talk from elastic backscatter into the 407 nm channel even in the presence of low clouds that give rise to very strong elastic backscatter. We have also never observed other unwanted effects in our Raman channel like after-pulsing or strong signal induced noise. We therefore concluded that we detected inelastic scattering induced by the aerosol layer.

In the condensed phase, the Raman lines of $\mathrm{H}_{2} \mathrm{O}$ are widened to a rather broad band and shifted toward smaller wavelengths. The Raman spectrum of liquid cloud droplets overlaps with the spectrum of water vapor and thus with the transmission spectra of the filter in the $407 \mathrm{~nm}$ channel. Therefore, water clouds may interfere with Raman lidar measurements of water vapor. ${ }^{21}$ However, there is strong evidence against the interpretation that the inelastic signals that we have measured were created by Raman scattering from water. The Raman signal from condensed water is far to weak to be detected by our system. The size distribution retrieved from the elastic lidar backscatter as discussed above has a Volume density on the order of $5 \mu \mathrm{g} \mathrm{m}^{-3}$. If those particles were liquid water droplets the Raman backscattering coefficient would still be about 3 orders of magnitude below our detection limit even if we apply all the enhancement factors discussed by Melfi et al. ${ }^{21}$ We therefore came to the conclusion that the observed inelastic backscatter signal is a specific feature of the biomass burning aerosol layer and is not caused by water, neither liquid nor solid or in the gas phase.

Earlier in 2003, around June $1^{\text {st }}$ we have observed aerosol in an altitude of $13 \mathrm{~km}$ above the tropopause that showed a similar feature. It created a strong signal in the $407 \mathrm{~nm}$ channel that cloud not have been created by water of any phase. We interpreted this signal as fluorescence from the aerosol particles that were thereby identified of being of biogenic origin. ${ }^{22}$

\section{DISCUSSION}

The fluorescence of the aerosol accounts for an equivalent of roughly $1 \mathrm{~g} / \mathrm{kg}$ of water vapor (fig. 4). From the Raman scattering cross section of water which is about $8 \times 10^{-30} \mathrm{~cm}^{2} \mathrm{sr}^{-1}$, the scattering coefficient of the 
fluorescence can be estimated to be on the order of $10^{-13} \mathrm{sr}^{-1}$. Unfortunately, little is known about the cross sections of fluorophores like PAH on aerosol particles. Also, the efficiency of such a process in the atmosphere depends on many parameters including temperature and pressure hampering an assessment of the possibility of detecting the fluorescence from these agents by our lidar. However, measurements of cross sections of the fluorescence of bacteria and pollen are available, a value of $5 \times 10^{-14} \mathrm{~cm}^{2} \mathrm{~nm}^{-1}$ particle ${ }^{-1}$ for Bacillus globigii (Bg) and $2 \times 10^{-13} \mathrm{~cm}^{2} \mathrm{~nm}^{-1}$ particle $\mathrm{e}^{-1}$ for pine pollen when excited with light at $230 \mathrm{~nm}$ are reported by Stephens. ${ }^{23}$ Given a scattering cross section in this order of magnitude, a concentration of fluorescing particles of about $0.1 \mathrm{~cm}^{-3}$ is calculated from the measured backscatter coefficient using equation 3. If bioaerosol was responsible for the detected fluorescence, one out of 1000 particle should be a bioparticle. The concentration of bacteria in ambient air is 0.001 to $0.01 \mathrm{~cm}^{-324}$ and slightly below our limit of detection. An enhancement of bioparticles that may fluoresce is likely to occur in the plume of a forest fire.

Hegglin et al. ${ }^{6}$ reported that the fluorescence signal of sulphuric acid droplets that are contaminated with organic material is 2-3 orders of magnitude higher than the Raman signal from the water stretching vibration that they were trying to measure in the first place. We discussed above, that the Raman signal from aqueous aerosol particles of a number as inferred from the elastic lidar signals is about 3 orders of magnitude to weak to be detected with our lidar. Accordingly, the fluorescence of organic material could be strong enough to be measurable. The fluorescence of contaminated sulphuric acid droplets was reported to increase as the concentration increases and the aerosol ages. ${ }^{6}$ The content of internally mixed sulfate increases as a biomass burning plume ages. ${ }^{25}$ An aerosol as investigated by Hegglin et al. ${ }^{6}$ is a good candidate for creating fluorescence in detectable strength.

These considerations demonstrate, that fluorescence should be taken into account when analyzing Raman lidar signals in the presence of polluted air. Even though the information that is currently available is to scarce to give a detailed quantitative analysis, we are confident that fluorescence from organic material is a reasonable interpretation for the inelastic scattering that we have detected from aerosol plumes in the troposphere and the lower stratosphere. The powerful laser, the large receiving telescope $(1.1 \mathrm{~m})$, and the large bandwidth $(5.7 \mathrm{~nm})$ and good performance of the $407 \mathrm{~nm}$ channel makes our system particularly suitable for detecting laser induced fluorescence from particles in the atmosphere. The decay time of the fluorescence signals of biologic material is on the order of $100 \mathrm{~ns}^{8}{ }^{8}$ In lidar measurements this delay would be interpreted as an altitude shift of about $15 \mathrm{~m}$. The maximum vertical resolution of $7.5 \mathrm{~m}$ of the lidar and the naturally rather diffuse vertical structure of aerosol layers, leads us to the conclusion that the finite lifetime of the excited states of fluorophores has no discernible effect on the lidar measurements.

\section{CONCLUSIONS}

During a measuring campaign in Lindenberg/Germany we have detected inelastic scattering from an aerosol layer in the upper troposphere. We showed that Raman scattering by water cannot explain the observation and we are confident that the signal is not an instrumental artefact. In the literature numerous reports describe the fluorescence of particles that are likely to be present in aerosol released by biomass burning. Fluorescence spectra of such particles are detectable by our lidar set-up. All these examples have in common, that organic compounds need to be present to create the fluorescence. Therefore, we conclude that atmospheric aerosol of biogenic origin may fluoresce when excited with a laser and that this fluorescence interfered with the water vapor measurement of the $407 \mathrm{~nm}$ Raman channel. The detection of fluorescence from atmospheric aerosol by a lidar has not yet been reported anywhere in the literature. However, it is the most plausible explanation for our experimental results.

Reliable data on the fluorescence of aerosol is scarce and therefore it is difficult to give an assessment on the potential impact of aerosols on the accuracy of water vapor measurements performed with a Raman lidar. Aerosol particles originating from biomass burning are abundant throughout the upper troposphere and even the lower stratosphere also outside of the plumes. ${ }^{25}$ The particle concentration in the background regime are some orders of magnitude lower than in the plumes. Water vapor concentration in the upper troposphere decreases rapidly with altitude. At the tropopause its concentration is about 2-3 orders of magnitude lower than in the lower troposphere. In this region a precise water vapor measurement is essential for currently very intensively investigated problems like the formation of subvisible cirrus and contrails. Ambient biogenic aerosol could have a severe impact on Raman measurements of water vapor in this region. However, its influence can be limited 
by using narrowband filtering. On the other hand the fluorescence of aerosol offers the opportunity to study the origin of aerosol by a remote sensing technique. The assessment of the impact of aerosol on global climate could greatly benefit from exploring these possibilities.

\section{ACKNOWLEDGMENTS}

We like to thank the British Atmospheric Data Centre for providing access to ECMWF data and performing trajectory calculations. Special thanks to Ingo Beninga, Wilfried Ruhe (impres GmbH) and the staff at MOL for assisting the experiments. We particular like to thank Dirk Engelbart from the MOL, who provided the radiosonde data and made the campaign possible.

\section{REFERENCES}

1. R. Neuber, P. von der Gathen, and U. von Zahn, "Altitude and temperature of the mesopause at $69^{\circ} \mathrm{N}$ latitude in winter," J. Geophys. Res. 93(L03688), pp. 11093-11101, 1988.

2. U. von Zahn and J. Höffner, "Mesopause temperature profiling by potassium lidar," Geophys. Res. Lett. 23(L03688), pp. 141-144, 1996.

3. E. J. Brinksma, Y. J. Meijer, I. S. McDermid, R. P. Cageao, J. B. Bergwerff, D. P. J. Swart, W. Ubachs, W. A. Matthews, W. Hogervorst, and J. W. Hovenier, "First lidar observations of mesospheric hydroxyl," Geophys. Res. Lett. 25(L53561), pp. 51-54, 1998.

4. R. Schultze, M. Lemke, and H.-G. Löhmannsröben, "Laser-induced fluorescence (LIF) Spectroscopy for the in situ analysis of petroleum product-contaminated soils," in Laser in environmental and life science, S. S. Hering P., Lay J.P., ed., pp. 79-98, Springer, 2004.

5. G. Cecchi, D. Lognoli, and I. Mochi, "Fluorecence lidars and their potentials for the remote sensing of the marine environment," Elsevier oceanography series, 69 , pp. 71-77, 2003.

6. M. Hegglin, U. Krieger, T. Koop, and T. Peter, "Technical Note: Organics-Induced Fluorescence in Raman Studies of Sulfuric Acid Aerosols," Aerosol Science and Technology, 36 , pp. 510-512, 2002.

7. I. Allegrini and N. Omenetto, "Laser-induced fluorescence and Raman scattering for real time measurement of suspended particulate matter," Env. Sci. Tec. 13(3), pp. 349 - 350, 1979.

8. R. Niessner, W. Robers, and A. Krupp, "Detection of particulate polycyclic aromatic hydrocarbons by laser-induces time-resolved fluorescence," Fresenius J. Anal. Chem., 341, pp. 207-213, 1991.

9. J. Fernández-Sánchez, A. Segura-Carretero, J. M. Costa-Fernández, N. Bordel, R. Pereiro, C. Cruces-Blanco, A. Sanz-Medel, and A. Fernández-Gutiérrez, "Fluorescence optosensors based on different transducers for the determination of polycyclic aromatic hydrocarbons in water," Ana. Bioana. Chem. 377(4), pp. $614-$ $623,2003$.

10. T. Behymer and R. Hites, "Photolysis of polycyclic aromatic hydrocarbons adsorbed on fly ash," Env. Sci. Tec. 22(11), pp. $1311-1319,1988$.

11. C. Schauer, R. Niessner, and U. Pöschl, "Analysis of nitrated polyaromatic hydrocarbons by liquid chromatography with fluorescence and mass spectrometry detection: air particulate matter, soot and reaction product studies," Ana. Bioana. Chem. 378, pp. 725-736, 2004.

12. S. C. Hill, R. G. Pinnick, S. Niles, Y.-L. Pan, S. Holler, R. K. Chang, J. Bottiger, B. Chen, C.-S. Orr, and G. Feather, "Real-time measurement of fluorescence spectra from single airborne biological particles," Field A.C.T. 3(4-5), pp. 221-239, 1999.

13. S. Christesen, C. Merrow, M. DeSha, A. Wong, M. Wilson, and J. Butler, "UV fluoresence lidar detection of bioaerosols," SPIE, Vol. 2222 , pp. 228-237, 2004.

14. H.-J. Schäfer, O. Schrems, G. Beyerle, B. Hofer, W. Mildner, F. Theopold, W. Lahmann, C. Weitkamp, and M. Steinbach, "A modular and mobile, multi-purpose lidar system for observation of tropospheric and stratospheric aerosols," SPIE EurOpto Series 2581, pp. 128-136, 1995.

15. A. Ansmann, U. Wandinger, M. Riesbel, C. Weitkamp, and W. Michaelis, "Independent measurement of extinction and backscatter profiles in cirrus clouds by using a combined Raman elastic-backscatter lidar," Appl. Opt. 31(33), pp. 7113-7131, 1992. 
16. S. Melfi, "Remote Measurements of the atmosphere using Raman scattering," Appl. Opt. 11(7), pp. 16051610, 1972 .

17. U. Leiterer, H. Dier, and T. Naebert, "Improvements in Radiosonde Humidity Profiles using RS80/RS90 Radiosondes of Vaisala," Beiträge zur Physik der Atmosphäre, Vol. 70 Nr. 4, pp. 319-336, 1997.

18. U. Wandinger, D. Müller, C. Böckmann, D. Althausen, V. Matthias, J. Bösenberg, V. Weiss, M. Fiebig, M. Wendisch, A. Stohl, and A. Ansmann, "Optical and microphysical characterization of biomass- burning and industrial-pollution aerosols from multiwavelength lidar and aircraft measurements," J. Geophys. Res. 107(D21), p. 8125, 2002.

19. F. Immler, "Lidar-Fernerkundung von troposphärischem Ozon und Aerosol in einer urbanen Umgebung," Dissertation., Freie Universität Berlin., 1999.

20. F. Immler and O. Schrems, "Vertical profiles, optical and microphysical properties of Saharan dust layers determined by a ship-borne lidar," Atmos. Chem. Phys. 3, pp. 1353-1364, 2003.

21. S. H. Melfi, K. Evans, J. Li, D. Whiteman, R. Ferrare, and G. Schwemmer, "Observation of Raman scattering by cloud droplets in the atmosphere," Appl. Opt. 36, pp. 3551-3559, 1997.

22. F. Immler, D. Engelbart, and O. Schrems, "Fluorescence from atmospheric aerosol detected by a lidar indicates biogenic particles in the lowermost stratosphere," Atmos. Chem. Phys. 5, pp. 345-355, 2005.

23. J. Stephens, "Measurements of the Ultraviolet Fluorescence Cross Sections and Spectra of Bacillus Anthracis Simulants," Final report, LOS ALAMOS NATIONAL LAB NM , p. 48, 1999.

24. P. Ariya and M. Amyot, "The role of bioaerosols in atmospheric chemistry and physics," Atmos. Environ. 38, pp. 1231-1232, 2003.

25. P. K. Hudson, D. M. Murphy, D. J. Cziczo, D. S. Thomson, J. A. de Gouw, C. Warneke, J. Holloway, H.-J. Jost, and G. Hübler, "Biomass -burning particle measurements: Characteristic composition and chemical processing," J. Geophys. Res. 109, p. D23S27, 2004. 